\title{
Testing the suitability of radio frequency identification cattle tags for tracking block cave progression
}

\author{
ML Wilson Rio Tinto, Australia \\ GJ Van Hout Rio Tinto, Australia \\ FF Dean Rio Tinto, Australia
}

\begin{abstract}
Modelling the upward progression of the cave back and the resulting downward flow of rock material within a block cave mine is critical to the safe and productive exploitation of an ore reserve. To this end, there have been many attempts, with varying degrees of success, to develop systems to enable the reliable gathering of information to produce data points of such a density as to assuage the concerns from geotechnical engineers and management. These systems, typically installed in concert with one another, range from the more elaborate and technical such as vast seismic arrays, beacons monitored in near real-time (Cave Tracker System) and active markers installed in the caving column (Smart Marker System), all the way down to surplus marked tyres placed on ground above the cave footprint.

This paper discusses the testing of a new system that would combine low-cost, passive, and long-lived markers with unobtrusive, low-maintenance, and relocatable detection hardware. This system would make use of recycled radio frequency identification (RFID) tags (small passive tags which use radio frequency excitation to transmit an identifying number to a detection system) and antennas currently employed by the cattle industry to test their practicality for use in a mining environment and its ability to supplement or replace some currently used technologies that are battery life reliant. After initial design and setup works, several rounds of testing were undertaken from late 2017 through mid-2018. These tests started with deployment of tags directly below the detection hardware for commissioning purposes through to putting tags through full loading and crushing cycles and monitoring their detection rates.
\end{abstract}

The results give confidence that refinement of the design and further testing is warranted with a view to deployment testing on other block cave operations within the Rio Tinto group.

Keywords: RFID, caving, instrumentation, monitoring

\section{Introduction}

The Argyle mine is located in the east Kimberley region of Western Australia, approximately 2,300 km northeast of the state capital, Perth. Discovered in 1979, the AK1 orebody was put into production in 1985 as an open pit operation with feasibility study works on a proposed underground block cave mine starting in 2002 (Ford 2011). Full underground development was approved in 2006 with the switchover from open pit to underground production occurring in 2013. The ore handling system for the mine is made up of two underground primary crushers fed from the hanging wall of the extraction level, dropping onto conveyor belts which transport material to the surface.

One of the major difficulties in managing caving operations is that one cannot physically see inside the caving void to monitor the cave back behaviour and observe how material within the muck pile moves, mixes and rills over the top.

It is not within the scope of this paper to discuss in detail the purposes of monitoring, however, it is important to highlight that the radio frequency identification (RFID) tag trial discussed in this paper serves mainly to assist the currently installed monitoring systems with tracking ore flow within the cave and provide data for 
back-analysis for flow simulators. It won't provide a direct means to determine the cave back or airgap at future mines and certainly not at Argyle as the cave has fully broken through to surface.

There are several instrumentation systems currently employed by the Argyle mine site to monitor the progression of the cave back and movement of material down towards the extraction level, the main three of which are the Smart Marker, Network Smart Marker (Steffen et al. 2016), and Cave Tracker systems (Whiteman et al. 2016). These systems work in different ways to reveal the same data to differing levels of detail. The Cave Tracker System can provide location coordinates for installed beacons on a frequency set prior to their installation, typically every two to three days, while the Smart Marker System provides only an installation point, known at time of installation, and its retrieval point, by monitoring each drive and determining where and when it was loaded from by inspecting production logs. Both these systems involve complex installation, the use of active beacons with limited battery life and are rather capital-intensive to setup, requiring engineering design and time-consuming installation by specialists. A system that uses passive beacons with a reduced infrastructure footprint would be a useful complement to these in block caving operations, especially if the consumable components are cheap enough to justify very dense installation arrays. RFID technology provided a good avenue for investigation in this regard.

Elexon Electronics, who currently supply and assist Rio Tinto with other instrumentation systems, were contacted for advice on the topic, and through intensive consultation, it was determined that an initial trial using recycled components used in the agriculture industry for the monitoring of livestock would be a good starting point.

\section{System components}

The equipment components selected for the detection part of the system comprised three 610 A\&B Dual Automated Race antennas (Aleis 2018a) and a Fixed Feedlot Wand 9060 (Aleis 2018b), all sourced from Aleis. The Fixed Feedlot Wand 9060 logs the detections made by the antennas of passing RFID tags and is connected to the site network using serial-to-IP adaptor hardware to enable remote monitoring of detections.

The other hardware includes an Allflex RD420 Handheld RFID Scanner, so tags can be read and logged prior to deployment, and the RFID cattle ear tags themselves. All items are shown in Figure 1.

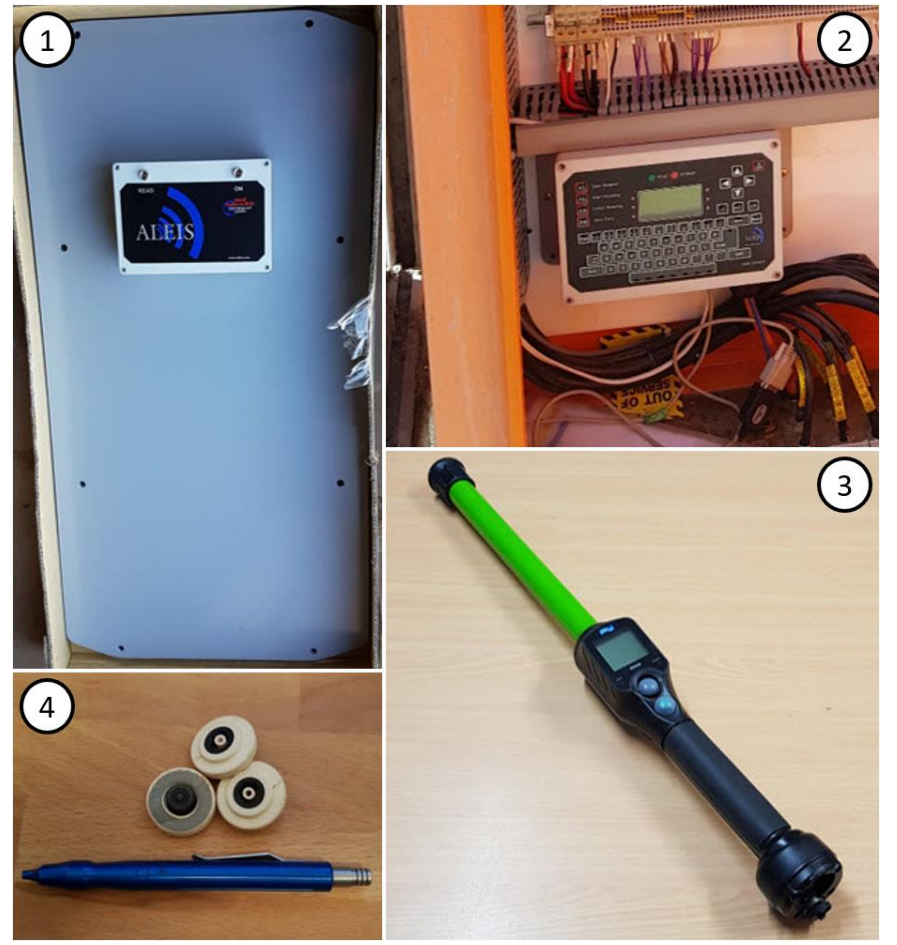

Figure 1 Components used in the trial (clockwise from top left; 1. 610 Multi A\&B Dual Automated Race Antennas, 2. Fixed Feedlot Wand 9060, 3. Allflex RD420 Handheld Scanner, 4. Cattle RFID ear tags) 
Monitoring systems like Smart Markers aim to detect the markers as close to the drawpoints as practically possible, often at the entrance of the extraction drive or at an orepass. This facilitates the process of determining what drawpoint the marker has been recovered from and providing the valuable information of how much those units have travelled laterally from their original position of installation.

The primary objective at the onset of this project was to assess if the naked and/or ruggedised RFID tags, ultimately having travelled through the cave, could actually be recovered in the first place. Tracing the tags back to from which drawpoint they were recovered will be a challenge for the next stage of the project, not discussed in this paper. This limited scope simplifies the set up to a single 'pick-up' location for the detection of the tags.

\subsection{System mounting location}

The tag detection occurs above a moving conveyor belt, tags and ore pulled from the drawpoints underground mine are transported to surface at Argyle by a conveyor belt system (Hersant 2004). The conveyor belt system, which moves at four metres per second and has a $1.4 \mathrm{~m}$ wide belt, is hung on chains from the backs to maintain a constant grade, which means the actual height above ground level can vary quite a bit.

To mount the panel antennas to ensure full coverage of conveyed material passing by, a frame was designed by an onsite draftsperson and constructed using fibre-reinforced plastic (FRP) beams. The choice of this non-conductive material was made as metallic components would reduce the effectiveness of the RFID system.

Determining where to mount the detection system presented several challenges. It had to be located on one of the conveyors, in such a way that the maximum amount of tags deployed would travel past the detection system but in such a spot that installation, removal, and troubleshooting work would not significantly interfere with the normal servicing and operations of the ore handling system.

The first thought was to install it as close to the bottom of each crusher as possible, either on the CV102 conveyor that services the fine ore bin below Crusher 2 (Figure 2) or on the lower extreme of CV103 just above the CV102/103 transfer station (Figure 3). At those sites, there is access to both sides of the conveyor for maintenance and convenient power supply. Both locations were investigated and eventually dismissed for a combination of reasons, primarily focused around the difficulties that would be encountered during the installation process and conflicts that would arise when shutdown servicing of the conveyors in these locations were undertaken. Furthermore, it was difficult to come up with a frame design that could get around the fire lines (red triangle on Figure 2) and the manual safety shutdown line (red line on Figure 2), whilst also not mounting too close to the rollers and conveyor belt itself.

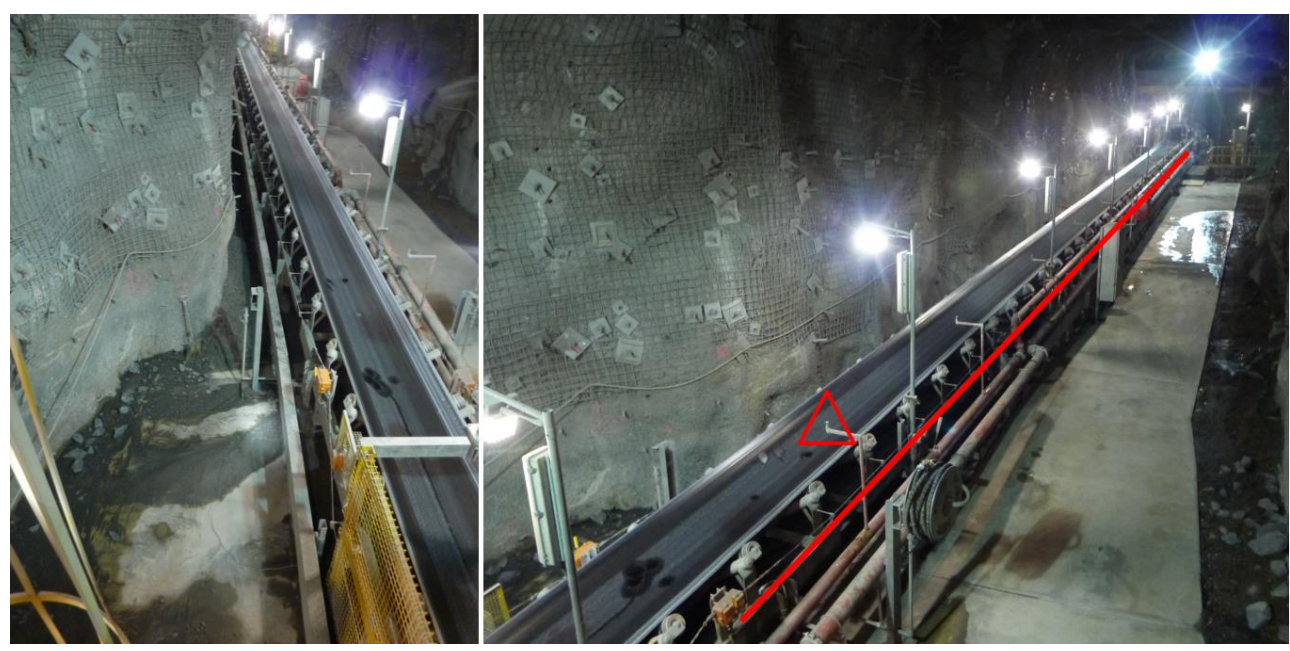

Figure 2 Proposed mounting location for detection system on CV102 


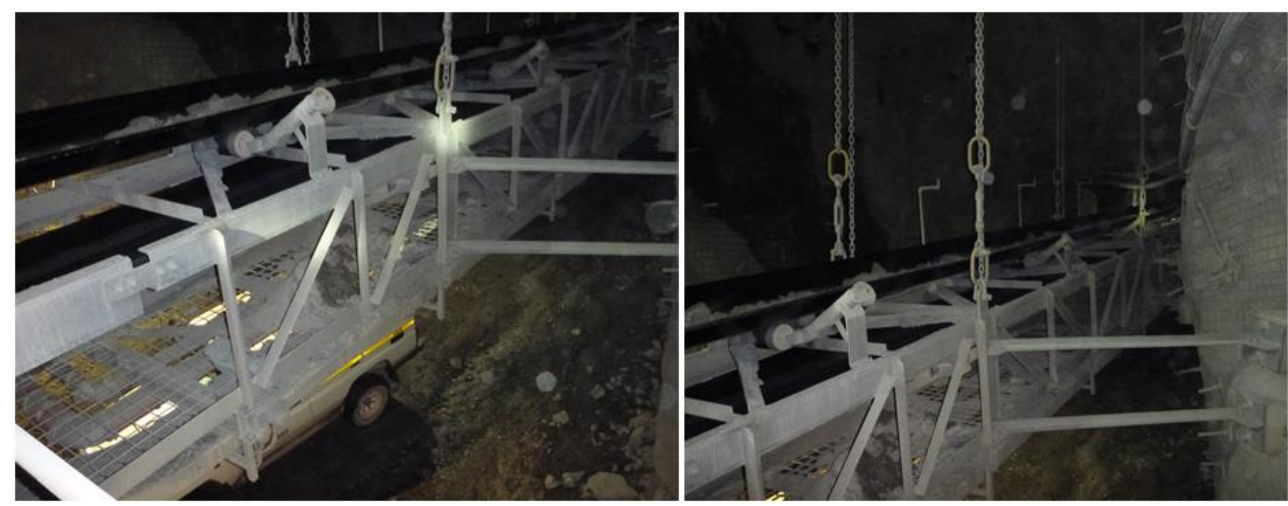

Figure 3 Proposed mounting location for detection system on CV103 above CV102/103 Transfer Station

Erecting scaffolding over the top of the CV102 conveyor and using that as a frame mount was dismissed because it was not considered a good option for the long-term and would require a conveyor shutdown to construct, which would adversely impact production activities.

Once these two most prospective underground locations were dismissed, surface solutions were considered. There are two conveyors on-surface prior to the secondary crushing circuit, those being the tail end of CV104 (Figure 4) and CV109. Due to CV109 intermittently being bypassed for dumping directly to stockpile, it was excluded at an early stage and works begun on selecting a position on the final section of CV104. The tail end of CV104 was originally excluded due to the high amount of steel lattice work and the concern that the (untested) system components would not be protected anymore within the underground conveyor drives. Outside the conveyor decline, the components will be exposed to the weather elements (heat, dust, high winds and rain) that can be harsh in that part of Australia, raising the probability that some steelwork would be required in the frame to give it some degree of rigidity.

The area immediately to the north of CV104 provides ample space for crane access, and through close coordination with the fixed plant team, a suitable position was decided on and planning work began on the frame. Once the mechanical engineers approved the construction of a frame to attach directly to the conveyor itself (in particular onto the 'stringers', Figure 4 bottom right), the boiler makers could start with building a frame on which to mount antennas. Elexon Electronics recommended not to install the antennas close to the steel girders (bottom left Figure 4 ) and, therefore, the only option remaining was to mount the system above this section of conveyor structure.

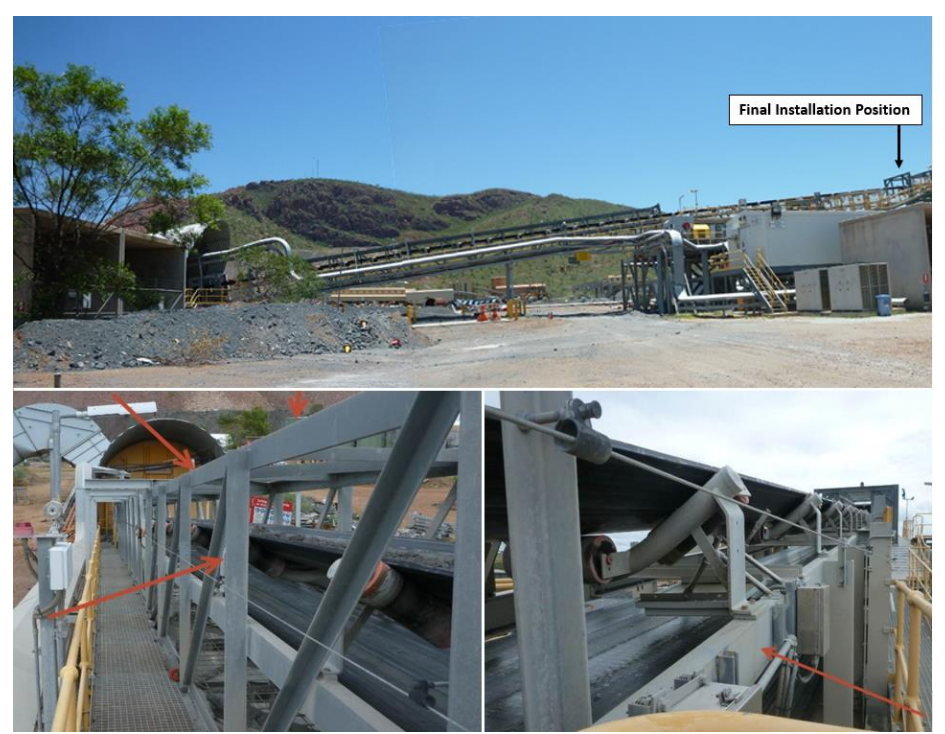

Figure 4 Proposed mounting location for detection system on tail end of CV104 on-surface (top). Bottom left: section with steel lattice work (arrows pointing to steel girders). Bottom right: section without lattice, arrow indicates the stringers onto which the frame can be bolted 


\subsection{Frame construction and setup}

A preliminary design note was put together by Elexon Electronics to give an idea of how a frame could be put together such that the three antennas provided the best coverage of the conveyor when mounted. As per Figure 5, this initially consisted of two vertically mounted antennas on the sides and one mounted horizontally from beneath. The reasoning for this is that specific alignments of the RFID tags could possibly reduce the ability of a single antenna to detect them. By having two mounting axes with an offset, the chance that a tag will be picked up increases and it reduces the number of tags missed through unfavourable placement within the material moving past.

The initial design proposal, with an antenna underneath the conveyor, was modified due to the tight tolerances that would be encountered trying to mount an antenna between the top and bottom conveyor belt runs. This was done by switching to a top-mounted horizontal antenna (Figures 6 and 7).

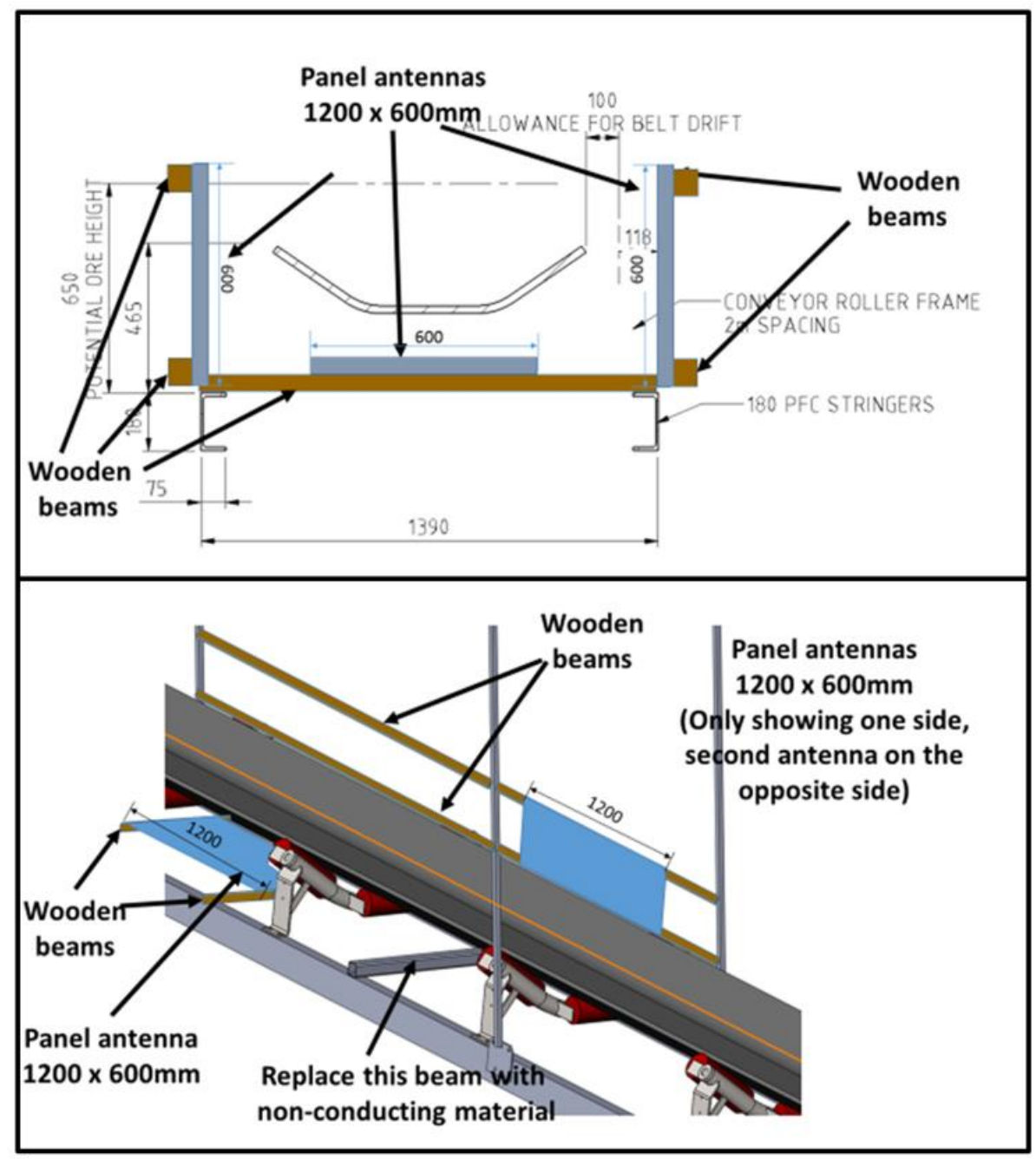

Figure 5 Initial mounting design idea sketches proposed by Elexon Electronics (Steffen, pers. comm., 17 Feb 2016) 


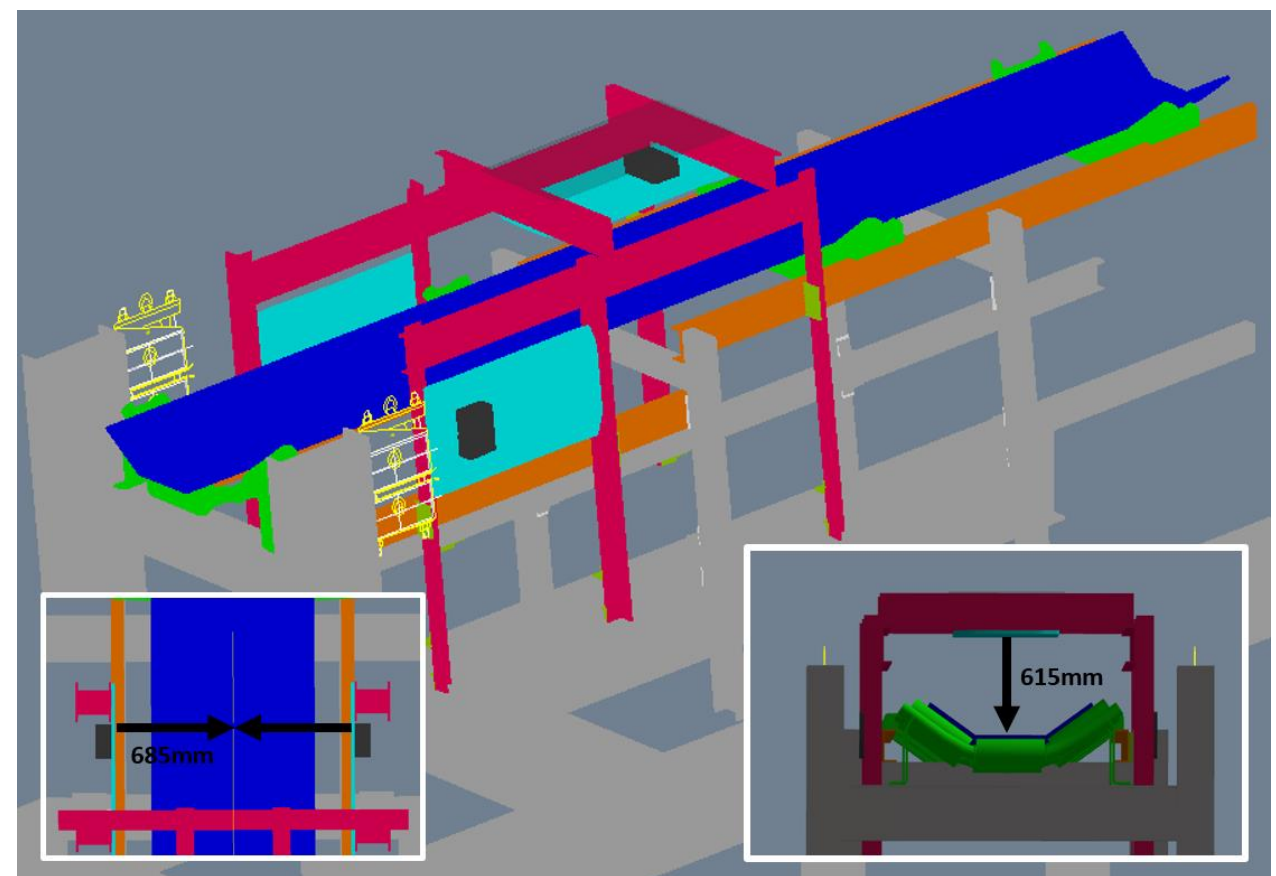

Figure 6 Isometric view of frame design drawings (frame components in red, conveyor belt in dark blue, CV104 structure in grey, antennas in light blue, belt clamp mounting position shown in yellow). Bottom left inset: plan view showing side antenna distance from centre of belt. Bottom right inset: slice view showing vertical antenna distance from centre of belt

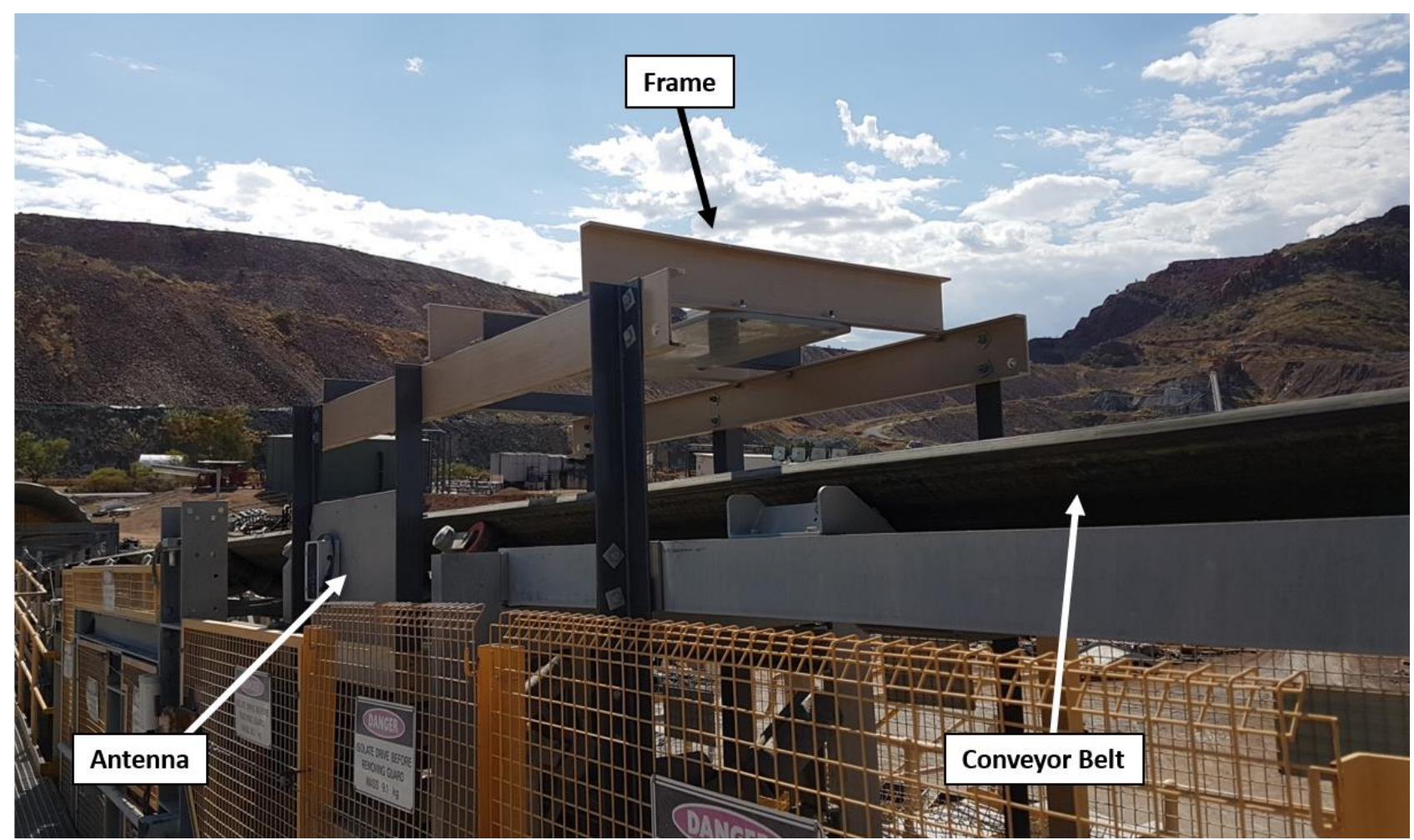

Figure 7 Final frame and antenna setup installed on CV104

Another constraint on design was that the distance between the conveyor belt base and the top antenna, or in the case of the side antennas on the opposite side of the conveyor, should not exceed 1,200 $\mathrm{mm}$ and should be mounted as far from electrical noise as practical. 
Due to the nature of RFID technology, the system frame had to be constructed with as little metal as possible to minimise interference or noise. The use of metal would reduce the chance of tag detection and decrease the effective range of the antennas. For this reason, the frame needed to be constructed out of FRP ' $I$ ' and ' $L$ ' beams (Figure 6). Due to the construction material, the frame was too flimsy and flexible, causing a number of issues during storage and mounting that required rectification prior to its final installation being achieved (Figure 7).

As shown on the insert of Figure 6, the actual distance from the top antenna to the conveyor is $615 \mathrm{~mm}$, far below the 1,200 $\mathrm{mm}$ mentioned above and still at a safe distance from the rock on the moving conveyor. This horizontal antenna was made sub-frame removable to allow for future belt hoisting. The side antennas are installed such that their face is $685 \mathrm{~mm}$ from the centre of the belt.

Regarding the location of the power and communications boxes, care had to be taken not to impede on the walkway and not to cross the trip wire barrier.

\section{$3 \quad$ Methodology and results}

The RFID tags used in this trial were recycled cattle ear tags sourced from the livestock industry and kindly provided for free by Elexon Electronics. Once used, they are considered unusable by the livestock industry as an identification number can only be used once. However, they are still in perfect working order and thus considered as good as new tags for the purposes of our trial. One of the questions the trial aimed to answer was whether these tags would survive the mining cycle in their original unprotected state, or whether they would require ruggedisation in subsequent testing or full implementation.

The testing started with deployment of tags directly below the detection hardware for commissioning purposes through to putting tags through full loading and crushing cycles. The testing rounds were split into four initial categories to assess the effect of different parts of the mining process and ore handling infrastructure on detection rates of tags; the deployment positions being shown in Figure 8. All tags for each round were scanned with the handheld scanner and logged prior to their redeployment so detection rates could later be determined.

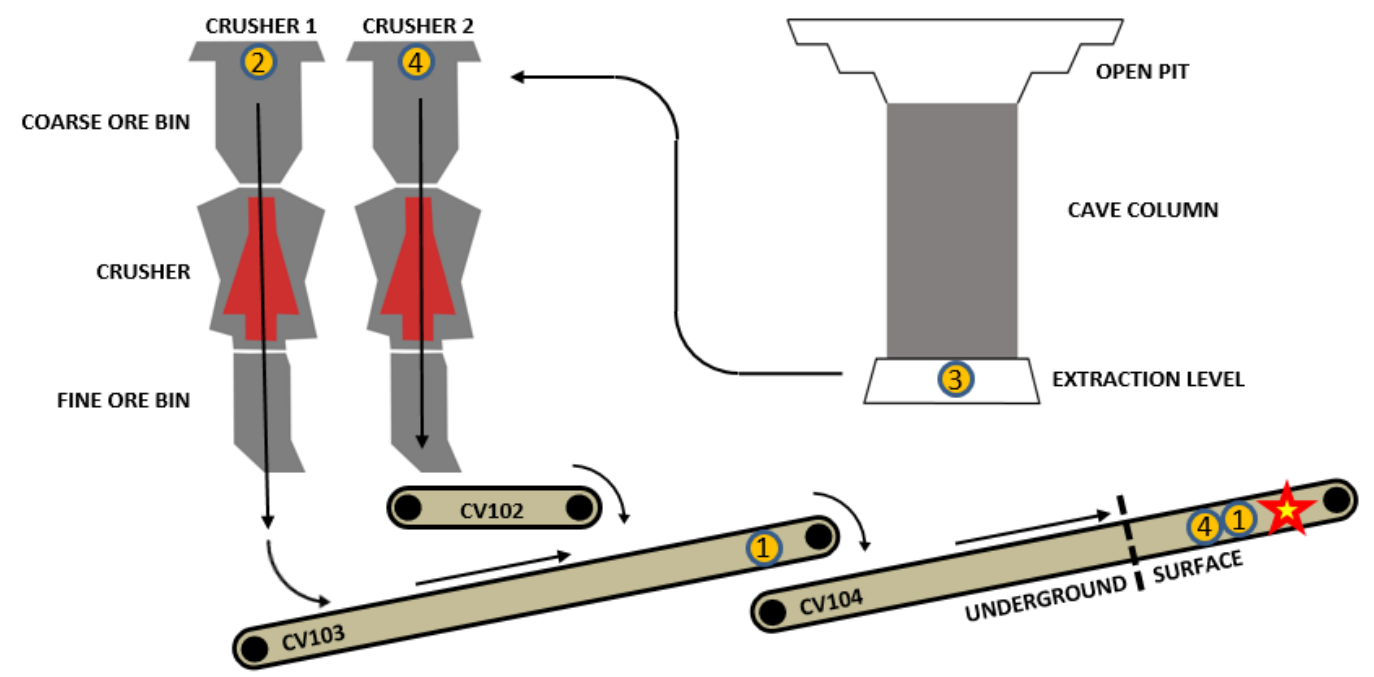

Figure 8 Schematic location within the mining cycle each testing round (number indicated by orange circles) started. Dashed line on CV104 indicates where it emerges on the surface

Initial testing of the tags, in the workshop, by waving those in front of the antennas showed that the tags were picked up at a distance of about $1.5 \mathrm{~m}$, adequate for being picked up from the frame above the belt. The next test was to put a tag in a gumboot and walk through the middle of the frame, the tag read. Then, one was put into a plastic bucket of broken rocks and this was walked through, it also read. Lastly, somebody moved through the antennas at a safe running speed holding the plastic bucket of broken rocks with the tag buried in it, it also read. 
The first tests after the frame was mounted onto the CV104 were not successful. None of the 50 tags thrown onto the belt were read. Elexon Electronics engineers confirmed that the belt speed should not be a problem and suspected that the readers were likely affected by electrical noise caused by motors or other electrical equipment. They provided instructions to read the noise levels from the antennas so that this hypothesis could be verified and that the noise source could be identified. The two antennas that showed high noise levels were damaged during the frame construction, causing a major issue with the system's ability to pick up anything. In order to replace the faulty antennas, the frame was lifted from the conveyor and was unfortunately storm damaged while being stored outside the electrical shed, requiring repairs. During the testing, before mounting the frame back onto the $\mathrm{CV} 104$, it was revealed that one of the printed circuit board $(\mathrm{PCB})$ boxes was also physically damaged, requiring replacement.

Noise level testing while the belt was operating revealed that noise levels were about double that of when testing the antennas in the electrical shed.

When all reading units were back in working condition, a small test by throwing a few tags on the belt showed that all were picked up by the antennas. This invoked the next step to make the installation position more permanent. Electrical and networking were up to this stage temporary, and when doing anything with the system, the presence of an electrician and barricading was required. A permanent electrical power hook-up and further enhancements to the data reader box to automate the storage and output of tag IDs to csv format files were worked on simultaneously. The software package provided by Aleis (Tag Manager v 2.0.12.3) is used to get data off the data readers.

\subsection{Testing round $1-$ CV104 and CV103 entry point}

The first round of testing was split into two subsections (see Figure 8 positions indicated by ' 1 '); the commissioning phase with tags dropped onto the CV104 conveyor, and a second phase to test any detection rate change introduced by tags passing through the CV103/CV104 Transfer Station.

Commissioning tests in May and November 2017 on CV104 produced detection rates of $70-73 \%$, whilst the tags dropped on CV103, which went through the CV103/104 Transfer Station before travelling up CV104 and past the antenna setup, recorded a 74\% detection rate. It must be noted that half of the 'misses' were tags bouncing off the conveyor when being dropped onto the moving conveyor belt that is already loaded with material. The tags tend to bounce off rocks. It is postulated that there would be less bouncing if the tags are mixed in with the rock material, although there may be less tag registration because they are buried. This is very hard to validate as one would not want to stop the ore artery of the mine to check this.

The detection rates were considered very encouraging and it was decided to go over to the next phase of testing, further up the ore stream.

\subsection{Testing round 2 - tipple entry point}

The second round of testing moved to an earlier stage of the ore handling cycle where tags were deployed into the top of the Northern Crusher Extraction Level Tipple (see Figure 8 position indicated by ' 2 '). These tags travelled through the coarse ore bin, through the primary crusher, the fine ore bin, transfers onto CV103, through the transfer station, and up past the antennas setup on CV104 on-surface. Of the 400 tags deployed, 219 were detected; a 55\% read rate which is considered a good number, given the fact that the cattle ear tags were not designed for the harsh mining environment.

Whilst undertaking $Q A / Q C$ on the antenna system during this round of testing, it was discovered that the two vertically mounted antennas (on each side of the conveyor) were not responding as previously to test tags placed in their vicinity; one not responding at all and the other having a reduced detection range (down to $\sim 500 \mathrm{~mm}$ from an original $\sim 1,200 \mathrm{~mm}$ ). The horizontally mounted antenna (on top of the frame) was still in full working order.

Due to operational constraints, it was decided to leave the system antennas in place and continue testing. A request was sent to Elexon Electronics to modify the software so that it not only recorded what tags passed 
the antennas but also what antenna detected the tag. A rather simple procedure with a few lines of coding, using a serial connection to the master reader via a terminal program at 9,600 baud, was used to configure the readers to log the detections separately for each reader. After this modification, it became clear that only one antenna, the horizontal one above the conveyor belt, was detecting the recorded tags.

One side antenna, previously working when waving tags next to it, was found to be defective while the other side antenna, still working, had not picked up any tags from the belt despite being the first antenna the tags pass when the belt is moving. The preliminary conclusion is that only the horizontal antenna picks up tags on the moving conveyor belt and the vertical antennas do not provide any useful redundancy to the detection system.

\subsection{Testing round 3 - drawpoint entry point}

The third round shifted to testing any reduction in detection rates through the load/haul/dump cycle undertaken on the extraction level (see Figure 8 position indicated by ' 3 '). Two separate bags of tags were scanned and assigned to be dispersed into two separate drawpoints.

The first bag was assigned to $12 \mathrm{~N} 1$ with the tags being deployed loose by hand. This location is loaded directly to the Southern Crusher Extraction Level Tipple which would have the tags follow much the same path as that described in testing round 2 with the addition of travelling on CV102 before being dropped onto the CV103 conveyor at the CV102/CV103 Transfer Station. This set of tags achieved a 44\% detection rate at surface. The second bag was assigned to $13 \mathrm{~N} 10$. Material from this drawpoint is first transferred to a stockpile on the extraction level footwall, then rehandled to a tipple. This set of tags achieved a $49 \%$ detection rate at surface.

During this testing round, the wireless connection to the RFID logger on CV104 became active and working reliably, allowing the geotechnical engineers to log into it remotely from their network connected computers in the office; a fantastic bit of networking by staff from the mine and the site communications engineering team.

\subsection{Testing round 4 - resin-encased tags}

A small fourth round of testing was undertaken to assess the detection rate of tags encased in the resin used for rock mass consolidation within the extraction level at the mine (see Figure 8 positions indicated by ' 4 '). Tags were placed into $50 \mathrm{~mm}$ diameter cups used for recovering unconfined compressive strength test samples of resin and then dropped in two different locations, those being the CV104 conveyor and the Southern Tipple. The CV104 samples returned a detection rate of $35 \%$ while the Southern Tipple samples showed a $20 \%$ reading rate. This reduced rate is discussed further in Section 4.1 and will be the subject of further testing works as noted in Section 5.

\section{Discussion}

\subsection{Summary of results}

A summary of the detection rate results to the end of March 2018 is presented in Table 1 . They show that the tags used, in their unprotected state, still exhibit detection rates above $40 \%$ when transiting the mining cycle from drawpoints to surface. This rate, much higher than the author's initial expectation of $5-10 \%$, is an encouraging sign for the usefulness of the technology.

One area of concern is the resin-protected sample group which produced rates of 20 and $35 \%$ from the two deployment locations. This group was a small-scale test which will need to be expanded upon. The drillholes that these types of tags would be installed into in a future block cave operation would more likely be filled with a grout mixture of cement and water, as such a larger test group using tags encased in this material is envisaged for future phases. 
Table 1 Summary of testing round detection results to end of March 2018. Test round names coincide with location numbers on Figure 8

\begin{tabular}{lllll}
\hline Test round & Location & Tags deployed & Tags detected & Detection rate \\
\hline 1a & CV104 & 33 & 24 & $73 \%$ \\
1b & CV103 & 100 & 74 & $74 \%$ \\
\hline 2 & Tipple 1 & 400 & 219 & $55 \%$ \\
3a & $12 N 1$ & 100 & 44 & $44 \%$ \\
3b & $13 N 10$ & 103 & 50 & $49 \%$ \\
4a & CV104 & 20 & 7 & $35 \%$ \\
4b & Tipple 2 & 20 & 4 & $20 \%$ \\
\hline
\end{tabular}

\subsection{Antenna failures}

As noted previously, it was discovered during the second round of testing that the two side antennas were no longer performing when tags were waved next to them. This prompted consultation with the equipment suppliers so the logger could be reprogrammed to report which antenna was reading each tag as it went past, in addition to its RFID number and time stamp. The cause of the antenna degradation is still not known at the time of writing. This will be investigated further at a later stage.

\section{$5 \quad$ Further work}

Ongoing monitoring will continue with the initial version of this system as tags dropped into the open pit make their way through the mining cycle. However, planning is underway to modify components for a proposed second phase.

Current hardware used in the test was manufactured for a specific use case - the identification of cattle. This, while perfect to test the viability of the technology, could possibly be improved by switching to different model equipment. However, consultation with technical experts will be required first. Part of this review will focus on whether detection range increases are possible without drastically increasing the cost of the equipment required.

Suitable installation locations will change, depending on which site the next trial occurs. However, easier accessibility will be a major consideration in the redesigned frame setup.

During the early part of this testwork, it was thought that any second phase detection structure would take the shape of an arch over a conveyor with an increased number of narrower RFID antennas as this would increase the number of detection orientations available, thereby increasing the chance of tag detection. However, given the results so far, thoughts are turning towards decreasing the number to two.

Further first phase testwork is currently underway for determining the survivability of the unprotected tags entering the top of the cave column from surface. This data will continue to accumulate over the next two years as the cave is drawn down.

Part of the second phase testwork will be larger tag sets encased in material to determine the effect of typical installation conditions on detection rates. This will predominantly focus on cement encasement. However, other materials will also be considered, depending on other use cases identified. 


\section{Conclusion}

The results garnered to date from this initial trial gives confidence that the technology could be suitable for the desired purpose. That is, the mass deployment of low-cost, passive RFID beacons within a cave column prior to production aid in the tracking of cave flow.

\section{Acknowledgement}

The authors thank Elexon Electronics, Brisbane for 5,000 tags free of charge, the assistance during the trial period, and help sourcing equipment for the trial. DronelView is acknowledged for their unmanned aerial vehicle support and advice regarding suitable payload configuration. The authors are further grateful to the staff at Aleis, Queensland for their product support. Last, but not least, the authors express their thanks to Rio Tinto for allowing the publication of this paper and the trial results contained within.

\section{References}

Aelis 2018a, 610 Multi A\&B (Cattle) Dual Automated Race Antennas, http://www.aleis.com/industrial/dual-automated-raceantennas/rfid-identificaton-cattle-610-multi-race-antenna

Aelis 2018b, Fixed Feedlot Wand 9060, http://www.aleis.com/industrial/fixed-feedlot-wands/handheld-reader-rfid-ffw9060

Ford, DC 2011, 'New life for the Argyle diamond mine - block cave style and beyond', Proceedings of the Eighth International Mining Geology Conference, Australasian Institute of Mining and Metallurgy, Melbourne, pp. 209-306.

Hersant, D 2004, 'Mine design of the Argyle underground project', in A Karzulovic \& MA Alfaro (eds), Proceedings MassMin 2004, Instituto de Ingenieros de Chile, Santiago, pp. 610-615.

Steffen, S, Poulsen, J, van As, A, Talu, S, Watt, G \& Ooi, JS 2016, 'Wireless system for monitoring cave-back propagation', in I Ross \& BA Sainsbury (eds), Proceedings MassMin 2016, Australasian Institute of Mining and Metallurgy, Melbourne, pp. 251-256.

Whiteman, D, Talu, S, Wilson, M, Watt, G, van As, A \& Kuiper, P 2016, 'Cave tracker flow monitoring system installation at Argyle diamond mine', in I Ross \& B-A Sainsbury (eds), Proceedings of MassMin 2016, The Australasian Institute of Mining and Metallurgy, Melbourne, pp. 479-490. 
